\title{
Soil and phytomicrobiomes for plant growth and soil fertility
}

\author{
Ajar Nath Yadav ${ }^{1^{*}}$, Divjot Kour ${ }^{1}$ \& Amrik Singh Ahluwalia ${ }^{2}$ \\ ${ }^{1}$ Department of Biotechnology, Dr. Khem Singh Gill Akal College of Agriculture, Eternal University, Baru Sahib, Sirmour 173 001, Himachal Pradesh, India \\ ${ }^{2}$ Department of Botany, Eternal University, Baru Sahib, Sirmour 173 001, Himachal Pradesh, India \\ *Email: ajar@eternaluniversity.edu.in
}

OPEN ACCESS

\section{ARTICLE HISTORY}

Received: 29 September 2021

Accepted: 15 October 2021

Available online

Version 1.0: 21 November 2021

\section{Check for updates}

\section{Additional information}

Peer review: Publisher thanks Sectional Editor and the other anonymous reviewers for their contribution to the peer review of this work.

Reprints \& permissions information is available at https://horizonepublishing.com/ journals/index.php/PST/open_access_policy

Publisher's Note: Horizon e-Publishing Group remains neutral with regard to jurisdictional claims in published maps and institutional affiliations.

Indexing: Plant Science Today, published by Horizon e-Publishing Group, is covered by Scopus, Web of Science, BIOSIS Previews, Clarivate Analytics, etc. See https:// horizonepublishing.com/journals/index.php/ PST/indexing_abstracting

Copyright: ( $)$ The Author(s). This is an openaccess article distributed under the terms of the Creative Commons Attribution License, which permits unrestricted use, distribution and reproduction in any medium, provided the original author and source are credited (https://creativecommons.org/licenses/ by/4.0/)

\section{CITE THIS ARTICLE}

Yadav A N, Kour D, Ahluwalia A S. Soil and phytomicrobiomes for plant growth and soil fertility. Plant Science Today. 2021;8(sp1):1-5. https://doi.org/10.14719/pst.1523

\begin{abstract}
Soil is the basic requirement for agriculture crop production and simultaneously the microbial activity is important to improve soil health for healthy crop growth because microbial communities play an important role in building a complex link between plants and soil. Microbiomes from plants, soil and extreme environments are naturally gifted with amazing capabilities which play significant roles in the maintenance of global nutrient balance and ecosystem functions. The microbiomes from diverse niches have in fact emerged as potential tools for improving the plant growth and productivity by diverse mechanisms include solubilization of nutrients, nitrogen fixation, hormonal stimulation as well as biotic and abiotic stress tolerance. Further, these microbiomes have an immense potential to maintain soil health and fertility. Thus, dependent on their mode of action and effects, these microbiomes can be used as biofertilizers, biopesticides, plant strengtheners, and phytostimulators which will play a major role in improving productivity and achieving sustainability in an eco-friendly, economical and cost effective manner.
\end{abstract}

Keywords: biodiversity, biofertilizers, biopesticides, mitigation, plant growth promotion, soil fertility, sustainability

Currently, production of grains is one of the major concerns of the agriculturists as world population is alarming to increase and 33\% of agricultural areas are reducing due to anthropogenic activities of humans. Soil and phytomicrobiomes are the hidden wonders that irrefutably play various roles for the ecosystem well-being have recognized to fix this one of the major problems of crop production and land reduction. In crop production, microbes inhabiting the soil and plant system could be used as bio-inoculants which naturally fulfil the plant nutritional requirement through chelating, fixing and solubilizing the nutrients present in soil and in atmosphere. These beneficial soil and plant microbiomes could be used for migration of diverse abiotic stress. The use of microbes on the in agricultural sustainability and other land also helps in the removal of the toxic substances that are major reason of the land degradation and increases the fertility of soil. The beneficial microbial communities colonize rhizosphere, phyllosphere or may be inhabitant of internal tissue of plants and also an important community of soil. The plant-microbe interactions open an opportunity to understand the interaction among soil microbiomes with plants and other living organisms. There is need to understand the functioning and potential applications of these communities in order to tackle the challenges of the future and ensure plant health and fitness. The applications of efficient microbes will be helpful in enhancing and improving sustainable agriculture and environ- 
mental stability (1). Soil is supporter of diversity of life and microbes have an infinite abundance. In soil eco-system, different types of micro creatures have been discovered including bacteria, fungi and archaea. Soil microbial population is known to vary with the type, habitat, available nutrients and light. It is known that the microbial population on the topsoil and depth of the soil is also varies where topsoil have tiny fraction of microbes and depth soil have more population of microbes. The populations of soil microbiomes have been explored from past few decades due to their several beneficial roles in the ecosystem (2-4).

The interface between plant ecosystem and soil is a region with high interaction among a numerous living microorganisms that affect plant growth, nutrients uptake, stress tolerance and biogeochemical cycles (Fig. 1). The rhizosphere is a complex environment where roots interact with physical, chemical and biological properties of soil. The specific content of root exudates create a niche that affects which microbes should colonize the rhizosphere, thus changing the composition and diversity of microbes that colonize the rhizospheric regions in a plantspecific way (5). Due to its dynamic nature and complexity, understanding the rhizosphere biology and activity of the rhizosphere is key to ensuring improved plant productivity and protections in the diverse agro-ecosystem. These soil and plant microbiomes play imperative roles in the growth and ecological fitness of their host. Microbial communities within the rhizosphere can affect plant welfare directly/ indirectly by affecting biomass and composition in the plant's natural ecosystem $(6,7)$. The study of these ubiquitous microorganisms by discovering their possible potential relationships with diverse plants has initiated a new and interesting area of research in rhizosphere microbiolo-

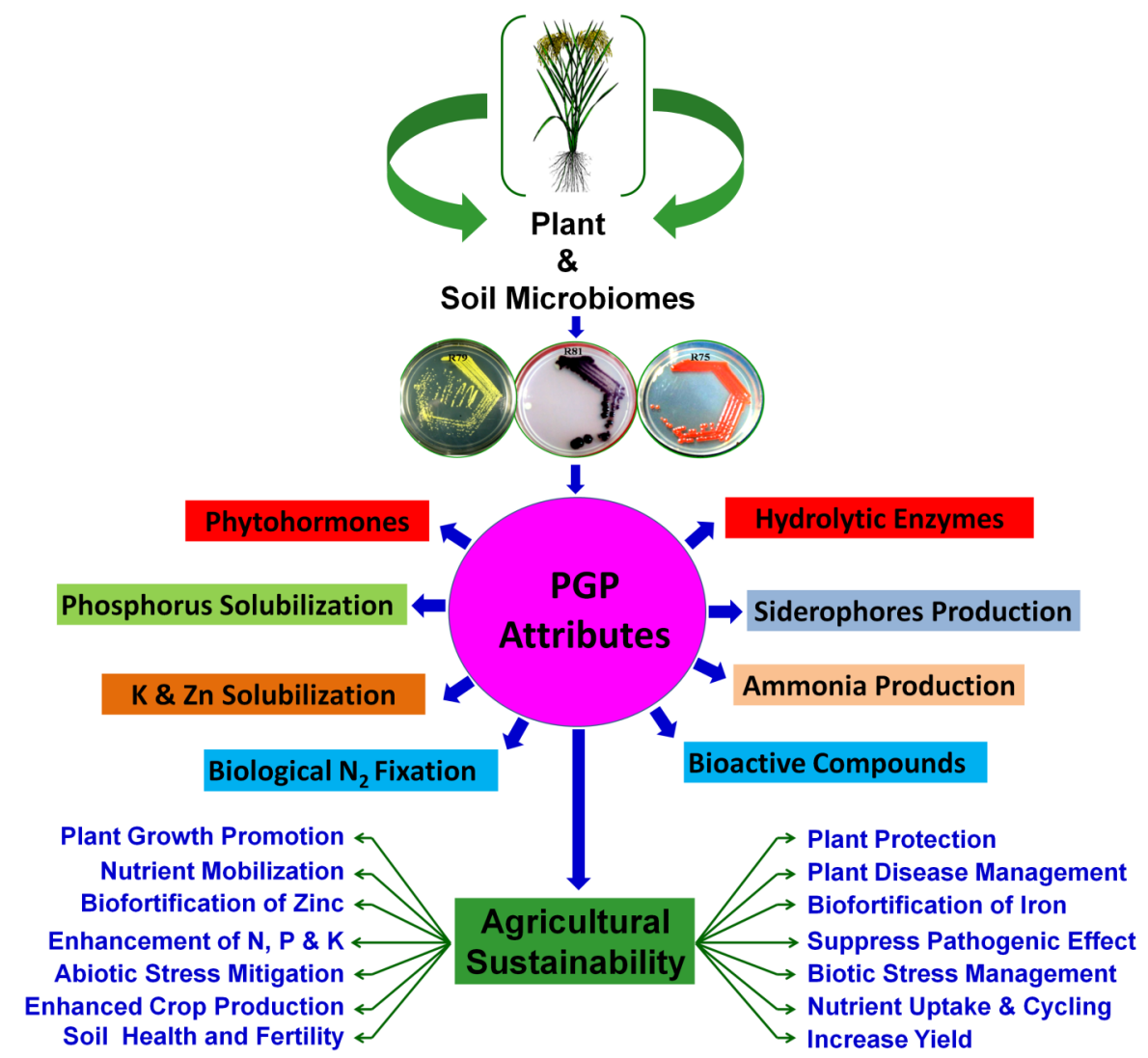

gy. These microbes increase plant growth and reduce susceptibility to diseases caused by phytopathogenic microorganisms such as nematodes, fungi, bacteria and viruses (8).

The term "endophyte" is a comprehensive topographic term which includes all organisms that colonize the living internal tissues of their hosts during the variable period of their life without symptomlessly. Endophytes have been reported from both monocotyledonous and dicotyledonous plants, ranging from woody tree species to herbaceous crop plants. Endophytes play a major role in promoting the growth and maintaining the health of the plants. Further, the endophytes are also known to be an amazing bioresources for novel bioactive compounds with anticancer, antifungal, antimicrobial and antiviral capabilities (9). The epiphytic microbiomes have been sorted out from each and every plant study and play significant role in plant growth and mobilization of beneficial nutrients (10). The aerial parts of living plants which include buds, flowers, fruits leaves and stems provide a habitat for microbes termed the epiphytic microbiomes. The dominant microbial inhabitants of the phyllosphere are bacteria though archaea, yeasts and fungi are also important inhabitants. The phyllospheric region is considered to be an important niche with agricultural and environmental significance. There is emergent evidence of imperative interactions of microbial inhabitants of the phyllospheric region that may affect the fitness of plant microbial population and that platy role in enhanced crop production (11).

Microbes are an integral part of soil and play major roles from re-cycling nutrients in the soil to influencing soil health. There are plant growth promoting (PGP) microbes which promote growth and maintain health of the plants by an assortment of mechanisms such as $\mathrm{N}_{2}$ fixation, production of different phytohormones and solubilization of insoluble minerals in the soil. There are huge number of publication on role of soil and phytomicrobiomes for plant growth and soil fertility (Fig. 2). Nitrogen is vital element for crop growth and is easily available in the air. Plants cannot utilize gaseous form of $\mathrm{N}$ and chemical fertilizers are applied to fulfill plant requirements and enhance the productivity. The disadvantages of using the chemical fertilizers have led to search of biological, cost effective and ecofriendly strategies. Biological nitrogen fixation (BNF) converts atmospheric $\mathrm{N}_{2}$ to plants usable forms (12). BNF is carried out by symbiotic nitrogen fixation (Rhizobium, Mesorhizobium, Bradyrhizobium and Azorhizobium), free living nitrogen fixation (Azotobacter) and associative symbiotic nitrogen fixation (Azospirillum).

Fig. 1. Soil and phytomicrobiomes, their plant growth promoting attributes and biotechnological applications 


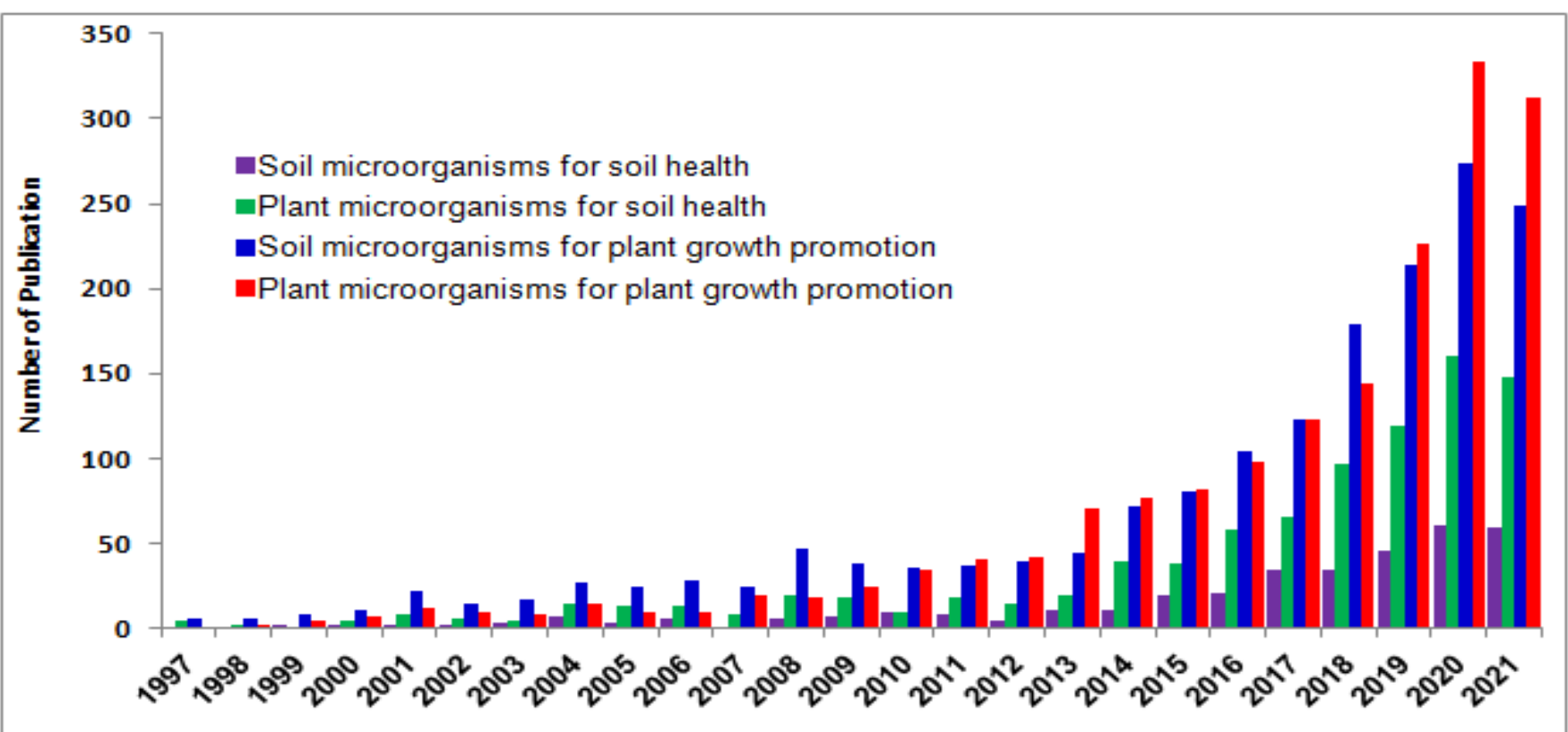

Fig. 2. Number of research publications on soil and plant microbiomes for plant growth promotion and soil health [Source-PubMed]

Phosphorus $(\mathrm{P})$ is the second important key macronutrient mevalonic acid with major role in the cell elongation, seed after nitrogen as a beneficial mineral nutrient for plant germination, and starch metabolism (20). Cytokinins regugrowth and development. Adequate phosphorus supply in late many important aspects of plant development and in the early stages of plant development is of major im- the response to abiotic and biotic stress (21). portance for development of reproductive parts of plant. The only alternative to circumvent P-deficiency is use of the phosphatic fertilizers. The chemical fertilizers presents high cost and are unsafe for the ecosystem. In order to reduce the use of phosphatic fertilizers phosphate solubilizing microbes (PSMs) are an effective and eco-friendly alternative. PSMs increase the availability of $P$ converting insoluble forms of $P$ into soluble forms which can be taken up by the plants (13). Potassium (K), is the $3^{\text {rd }}$ major macronutrient nutrient vital for plants with significant roles in the activation of several metabolic processes, including photosynthesis, protein synthesis, and enzymes, as well as in resistance to diseases (14). Soluble potassium concentrations in the soil are usually very low and exist in the form of silicate minerals and insoluble rocks (15). Zinc (Zn) is vital micronutrient and important constituent of an array of metabolic enzymes. It is the second most abundant transition metal in organisms after iron and the only metal represented in all six enzyme classes (16). Due to its poor mobility in plants, there is a need for a constant supply of available $Z n$ to fulfill plants requirements (17). Zn-solubilization is another potential capability of PGP microbes and thus can enhance the bioavailability of zinc. Phytohormones producing microbes are gaining full swing globally. Almost all the communication in plant cells is brought by plant hormones produced by plant cells or by rhizospheric microbes (18). The most commonly occurring phytohormones are auxins (indole acetic acid). Auxins play an essential role in the different cellular and developmental responses of plants across their lifespan. Auxins are involved in formation of vascular tissue, adventitious root initiation, tropistic responses, apical dominance and development of flowers and fruits. Auxins also affect cell division, enlargement and differentiation (19). Gibberellins (GAs) are diterpenes synthesized by the isoprenoid pathway from acetate and
The importance of soil is rapidly increasing at an alarming rate due to their benefits in the mankind. Food production is the major benefits which is increasing the soil importance among the human population. Soil, the represented of dynamic ecosystem and various resources, make the humans to think about its health and sustainability. Currently the health of the soil and ecosystem has been adversely affected by the anthropogenic activities of the humans during the period of green revolution (2). As alternative, microbes from the diverse habitats including soil as well as plants have known to fix such problems. Beneficial soil microbial and plant microbial communities are known to play key role in ecosystem services which are significant for our planet (22). They have a myriad of functions which plays imperative role in nutrients cycling including $\mathrm{C}, \mathrm{N}, \mathrm{P}$ and $\mathrm{S}$ and sustaining the soil fertility and plant growth by nutrients uptake (4). Beneficial microbes are also known to filter the waste water and play a noteworthy role in bioremediation of various environmental pollutants caused by different anthropogenic activities if mankind. All these different microbial ecosystem services have been maintaining and shaping the components of ecosystem (23).

Various microbes from the soil or plant habitat have been sorted out and known to been known to performs ecosystem and agronomical functions. Many extreme environments are found in nature which is actually too harsh to sustain a normal life. The diverse range of microbes survives and grows in the extreme environments and is known as extremophiles (24). Extremophiles associated with the plants growing under abiotic stress conditions possess different mechanisms to support and maintain health of the plants. The microbes reported from different plants growing under the harsh environmental conditions of water deficiency, $\mathrm{pH}$, salinity and temperature are said to be xero- 
philes, acidophiles, halophiles, thermophiles and psychrophiles respectively (25). The stress adaptive microbiomes have been reported from different phylum including Proteobacteria, Firmicutes, Euryarchaeota, Crenarchaeota, Basidiomycota, Bacteroidetes, Ascomycota and Actinobacteria (26). Extremophilic microbes with multiple PGP attribute positively influence the growth and productivity of the plants and could be used as biobased-microbial consortium under extreme conditions of abiotic stress. Abiotic stresses including acidity, alkalinity, drought, salinity, low and high temperature, are the most important limiting factor for agricultural productivity globally. Microbes are inhabitants of diverse range of environments and exhibit incredible metabolic abilities to mitigate diverse harsh environmental stresses (27). PGP microbes exhibit different mechanisms such as increasing the accumulation of osmolytes, production of ROS scavengers, increasing the availability of macro and micro nutrients and production of phytohormones to promote growth and improve tolerance of plants to abiotic stress $(28,29)$. These mechanisms improve the biochemical and physiological processes inside the plant cell and prevent the damage under abiotic stress. The ability of the microbes to confer plant stress tolerance will open a new avenue for mitigating the adverse effect of abiotic stress on agricultural crop production.

Biotic stress, the stress induced by the microbes and pests which causes several diseases on crops (30). This stress is considered as one of the major reason for the crop production loss up to total $30 \%$ worldwide. Usually pathogens present in soil are attracted by the root exudates and other chemical that causes diseases. In nature different types of plant pathogens are known such as bacteria, fungi, viruses and pests which can cause massive destruction to the plant crops by imbalancing the hormonal regulation, 6 nutrients and physiology. In agriculture fields variety of pesticides which are chemically synthesized were being used to combat biotic stress management and food requirement. But their overuse has been known to affect the environmental health adversely by causing pollution. Soil and phytomicrobiomes have also recognized as potent biopesticides which combat the biotic stress in a sustainable way through various mechanisms. Triggering of physiological and biochemical changes that induces resistance in plants and production of ROS are the mechanism that helps in the management of pathogens and pest.

In conclusion, the major challenges of $21^{\text {st }}$ century are environmentally sound and sustainable crop production. An enhanced production and healthy food is required to meet the demands of increasing population. To fulfill the demands and increasing the yield, chemical fertilizers are used which in turn are unsafe and unhealthy for the environment. Additionally the emerging plant pathogens continue to challenge the ability to safeguard plant growth and health globally. Abiotic stress is another global issue affecting plant growth and development and ultimately the productivity. Plant and microbial biotechnology though contributed to development of novel crop varieties with enhanced disease resistance, greater ability to tolerate abiotic stress and better nutritional value. Unfortunately, breeding strategies ignored the beneficial plant-microbe interaction which plays amazing roles in ecosystem functions for plants and soils. The beneficial soil and plant microbial communities could be used bio-inoculants for plant growth, enhanced crop production/protection, and mitigation of biotic and abiotic stresses for agro-environmental sustainability.

\section{References}

Yadav AN. Beneficial plant-microbe interactions for agricultural sustainability. Journal of Applied Biology and Biotechnology 2021;9(1):1-4. https://doi.org/10.7324/JABB.2021.91ed

2. Prasad S, Malav LC, Choudhary J, Kannojiya S, Kundu M, Kumar S et al. Soil microbiomes for healthy nutrient recycling. In: Yadav et al. (Eds). Current Trends in Microbial Biotechnology for Sustainable Agriculture. Springer, Singapore; 2021. pp. 1-21. https:// doi.org/10.1007/978-981-15-6949-4_1

3. Yadav AN. Phytomicrobiomes for agro-environmental sustainability. Journal of Applied Biology and Biotechnology 2021;9(5):1-4. https://doi.org/10.7324/JABB.2021.95ed

4. Yadav AN, Kour D, Kaur T, Devi R, Yadav A, Dikilitas M, Abdel-Azeem AM, Ahluwalia AS, Saxena AK. Biodiversity and biotechnological contribution of beneficial soil microbiomes for nutrient cycling, plant growth improvement and nutrient uptake. Biocatalysis and Agricultural Biotechnology. 2021;33:102009. https:// doi.org/10.1016/j.bcab.2021.102009

5. Grayston SJ, Wang S, Campbell CD, Edwards AC. Selective influence of plant species on microbial diversity in the rhizosphere. Soil Biology and Biochemistry. 1998;30(3):369-78. https:// doi.org/10.1016/S0038-0717(97)00124-7

Yadav AN, Kour D, Kaur T, Devi R, Yadav A, Dikilitas M et al. Biodiversity and biotechnological contribution of beneficial soil microbiomes for nutrient cycling, plant growth improvement and nutrient uptake. Biocatalysis and Agricultural Biotechnology. 2021;33:102009. https://doi.org/10.1016/j.bcab.2021.102009

7. Schnitzer SA, Klironomos JN, HilleRisLambers J, Kinkel LL, Reich PB, Xiao K, Rillig MC, Sikes BA, Callaway RM, Mangan SA. Soil microbes drive the classic plant diversity-productivity pattern. Ecology. 2011;92(2):296-303. https://doi.org/10.1890/10-0773.1

8. Yadav AN, Singh J, Rastegari AA, Yadav N. Plant Microbiomes for Sustainable Agriculture. Cham: Springer; 2020. https:// doi.org/10.1007/978-3-030-38453-1

9. Kour D, Rana KL, Thakur S, Sharma S, Yadav N, Rastegari AA, Yadav AN, Saxena AK. Disruption of protease genes in microbes for production of heterologous proteins. In: Singh HB, Gupta VK, Jogaiah $\mathrm{S}$, editors. New and Future Developments in Microbial Biotechnology and Bioengineering. Amsterdam: Elsevier; 2019. pp. 35-75. https://doi.org/10.1016/B978-0-444-63503-7.00003-6

10. Koskella B. The phyllosphere. Current Biology. 2020;30(19):R1143R6. https://doi.org/10.1016/j.cub.2020.07.037

11. Whipps J, Hand P, Pink D, Bending GD. Phyllosphere microbiology with special reference to diversity and plant genotype. Journal of Applied Microbiology. 2008;105(6):1744-55. https:// doi.org/10.1111/j.1365-2672.2008.03906.x 
12. Wani SP, Gopalakrishnan S. Plant growth-promoting microbes for sustainable agriculture. Plant Growth Promoting Rhizobacteria (PGPR): Prospects for Sustainable Agriculture: Springer;2019. pp. 19-45. https://doi.org/10.1007/978-981-13-6790-8_2

13. Kour D, Rana KL, Yadav AN, Yadav N, Kumar M, Kumar V, Vyas P, Dhaliwal HS, Saxena AK. Microbial biofertilizers: Bioresources and eco-friendly technologies for agricultural and environmental sustainability. Biocatalysis and Agricultural Biotechnology. 2020;23:101487. https://doi.org/10.1016/j.bcab.2019.101487

14. Verma P, Yadav AN, Khannam KS, Kumar S, Saxena AK, Suman A. Molecular diversity and functional annotation of potassium solubilizing bacteria associated with wheat (Triticum aestivum L.) from six diverse agro-ecological zones of India. Research Journal of Biotechnology. 2020;15:41-56. https://doi.org/10.1002/ jobm.201500459

15. Verma P, Yadav AN, Khannam KS, Saxena AK, Suman A. Potassiumsolubilizing microbes: diversity, distribution and role in plant growth promotion. In: Microorganisms for Green Revolution: Volume 1: Microbes for Sustainable Crop Production. Springer, Singapore; 2017. pp. 125-49. https://doi.org/10.1007/978-981-10-62414_7

16. Broadley MR, White PJ, Hammond JP, Zelko I, Lux A. Zinc in plants. New Phytol. 2007;173(4):677-702. https://doi.org/10.1111/j.14698137.2007.01996.x

17. Saravanan V, Madhaiyan M, Thangaraju M. Solubilization of zinc compounds by the diazotrophic, plant growth promoting bacterium Gluconacetobacter diazotrophicus. Chemosphere. 2007;66 (9):1794-98. https://doi.org/10.1016/j.chemosphere.2006.07.067

18. Maheshwari DK, Dheeman S, Agarwal M. Phytohormone-producing PGPR for sustainable agriculture. Bacterial Metabolites in Sustainable Agroecosystem: Springer; 2015. p. 159-82.

19. Luo J, Zhou J-J, Zhang J-Z. Aux/IAA gene family in plants: molecular structure, regulation and function. International Journal of Molecular Sciences. 2018;19(1):259. https://doi.org/10.3390/ ijms19010259

20. Vettakkorumakankav NN, Falk D, Saxena P, Fletcher RA. A crucial role for gibberellins in stress protection of plants. Plant and Cell Physiology. 1999;40(5):542-48. https://doi.org/10.1093/ oxfordjournals.pcp.a029575

21. Werner T, Schmülling T. Cytokinin action in plant development. Current Opinion in Plant Biology. 2009;12(5):527-38. https:// doi.org/10.1016/j.pbi.2009.07.002

22. Jansson JK, Hofmockel KS. The soil microbiome-from metagenomics to metaphenomics. Current Opinion in Microbiology. 2018;43:162-68. https://doi.org/10.1016/j.mib.2018.01.013

23. Kaur T, Devi R, Kour D, Yadav A, Yadav AN, Dikilitas M et al. Plant growth promoting soil microbiomes and their potential implications for agricultural and environmental sustainability. Biologia. 2021. 76: 2687-09. https://doi.org/10.1007/s11756-021-00806-w

24. Satyanarayana T, Raghukumar C, Shivaji S. Extremophilic microbes: Diversity and perspectives. Current Science. 2005:78-90. https://www.jstor.org/stable/24110434
25. Yadav AN. Biodiversity and bioprospecting of extremophilic microbiomes for agro-environmental sustainability. Journal of Applied Biolology and Biotechnology. 2021;9(3):1-6. https:// doi.org/10.7324/JABB.2021.9301

26. Yadav AN, Rastegari AA, Yadav N. Microbiomes of Extreme Environments. Boca Raton, USA: CRC Press, Taylor and Francis Group; 2020. https://doi.org/10.1201/9780429328633

27. Meena KK, Sorty AM, Bitla UM, Choudhary K, Gupta P, Pareek A, Singh DP, Prabha R, Sahu PK, Gupta VK. Abiotic stress responses and microbe-mediated mitigation in plants: the omics strategies. Frontiers in Plant Science. 2017;8:172. https://doi.org/10.3389/ fpls.2017.00172

28. Kour D, Rana KL, Yadav AN, Yadav N, Kumar V, Kumar A, Sayyed RZ, Hesham AE-L, Dhaliwal HS, Saxena AK. Drought-tolerant phosphorus-solubilizing microbes: Biodiversity and biotechnological applications for alleviation of drought stress in plants. In: Plant Growth Promoting Rhizobacteria for Sustainable Stress Management. Singapore: Springer; 2019. pp. 255-308. https:// doi.org/10.1007/978-981-13-6536-2_13

29. Kumar M, Yadav AN, Saxena R, Rai PK, Paul D, Tomar RS. Novel methanotrophic and methanogenic bacterial communities from diverse ecosystems and their impact on environment. Biocatalysis and Agricultural Biotechnology. 2021;33. https://doi.org/10.1016/ j.bcab.2021.102005

30. Yadav AN. Nanotechnology for agro-environmental sustainability. Journal of Applied Biolology and Biotechnology. 2021;9(4):1-6. https://doi.org/10.7324/JABB.2021.94ed 